\title{
Retinol-binding protein 4 in obese and obese-diabetic postmenopausal women in Montenegro
}

\author{
Aleksandra Klisic ${ }^{*}$, Adel Gouri², Verica Skerovic ${ }^{3}$, Milovan Jovanovic ${ }^{1}$, Nebojsa Kavaric ${ }^{1}$
}

1Primary Health Care Center, Podgorica, Montenegro, ²Laboratory of Medical Biochemistry, Ibn Rochd University Hospital, College of Medicine, Annaba, Algeria, ${ }^{3} \mathrm{Clinical}$ Center of Montenegro, Podgorica, Montenegro

\begin{abstract}
Introduction: Menopause is associated with an increase in visceral fat and obesity is the leading risk factor for insulin resistance (IR) and type 2 diabetes mellitus (T2DM). Recent evidence suggests that retinol-binding protein 4 (RBP4) is not an independent determinant of IR and its role in human glucose metabolism is not well clarified. We examined RBP4 and its association with IR, cardiometabolic and kidney parameters in obese postmenopausal women with and without T2DM.
\end{abstract}

Methods: Basic anthropometric, biochemical parameters, and blood pressure (BP) were determined in 50 obese diabetic and 50 obese non-diabetic sedentary postmenopausal women, and compared with 50 healthy normal weight controls.

Results: Higher levels of RBP4 were observed in obese individuals, as compared with normal weight group $(p=0.033)$. However, we did not find significant difference between obese non-diabetic and obese-diabetic individuals $(p=0.583)$. Serum RBP4 did not correlate with anthropometric measurements or any indicator of glucose metabolism in diabetic group, whereas RBP4 correlated with creatinine $(r=0.416, p=0.003)$, $\operatorname{eGFR}(r=-0.304, p=0.032)$ and triglycerides $(r=0.484, p<0.001)$. In obese non-diabetic group, correlations were observed with fasting glucose $(r=0.346, p=0.014)$, insulin $(r=0.292, p=0.038)$, HOMA-IR $(r=0.329$ $p=0.020), \operatorname{HbA1c}(r=0.326, p=0.021)$, creatinine $(r=0.399, p=0.004)$, eGFR $(r=-0.389, p=0.005), H D L-c$ $(r=-0.316, p=0.025)$, triglycerides $(r=0.461, p<0.001)$, and systolic $B P(r=0.286, p=0.044)$. In multiple regression analysis, triglycerides (Beta $=0.302, p<0.001$ ) and eGFR (Beta $=-0.188, p=0.015)$ were independent predictors of RBP4.

Conclusions: Serum RBP4 is not increased in obese type 2 diabetic postmenopausal women, but is associated with triglycerides and eGFR independently of diabetes.

Keywords: retinol-binding protein 4; postmenopausal women; obesity; type 2 diabetes mellitus

\footnotetext{
*Corresponding Author: Aleksandra Klisic, Center of Laboratory Diagnostics, Primary Health Care Center, Trg Nikole Kovacevica 6, 81000 Podgorica, Montenegro, Phone and Fax: +382 20481 999, E-mail: aleksandranklisic@gmail.com
}

Submitted: 20 November 2015 / Accepted 25 December 2015 DOI: http://dx.doi.org/10.17532/jhsci.2016.290

\section{INTRODUCTION}

Menopause per se is associated with an increase in total body fat and visceral fat (1). Recent study found $49 \%$ increase in abdominal fat and $22 \%$ increment of the subcutaneous fat in women in the postmenopausal stage, compared to premenopausal 
women (2). Obesity is the leading risk factor for insulin resistance (IR) and type 2 diabetes mellitus (T2DM). Women with a body mass index (BMI) of $30 \mathrm{~kg} / \mathrm{m}^{2}$ have about 28 times greater risk of developing diabetes than do women of normal weight (3).

Although considered as a part of Mediterranean basin, epidemiological data in Montenegro reported that $55.1 \%$ adults were overweight or obese (4) whereas the prevalence of diabetes in adults was $10.1 \%$ (5). However, the International Diabetes Federation estimates that these figures are not exactly in line with national statistics. According to local research and analyses, the number of persons with "latent" diabetes is 2-3 times higher than the estimated number of people with diabetes (6).

Obesity is characterized by changes in adipocytokines and activation of low-grade inflammation (7). Retinol-binding protein 4 (RBP4) is a recently discovered adipokine, which is potentially associated with IR and obesity (8). However, some other studies indicated that it is more likely linked with renal function (9).

Recent evidence suggests that RBP4 is not an independent determinant of IR (10-13). However, discrepant results are reported in the literature, and its role in human glucose metabolism is not well clarified (13). The purpose of the current study was to examine the association of RBP4 with parameters of glycemic control and IR, cardiometabolic and renal parameters in obese non-diabetic and obese diabetic postmenopausal women in Montenegro.

\section{METHODS}

\section{Study population}

We enrolled a total of 150 sedentary postmenopausal women (mean age 57.2 \pm 5.9 years) who volunteered to participate in the study. Menopause was defined as the absence of menstrual bleeding for more than one year. The participants were divided into three groups: normal weight $(\mathrm{n}=50)$, obese $(n=50)$ and obese diabetic ones $(n=50)$. Participants were consecutively recruited in the study when seeking gynecologic healthcare in the Primary Health Care Center in Podgorica, in a period from October 2012 to June 2013. All the participants completed a questionnaire including demographic characteristics, somatic illnesses, medications use, and lifestyle habits. Specific eligibility criteria included postmenopausal, sedentary $(<90 \mathrm{~min}$ of weekly exercise), normoalbuminuric women (urinary albumin excretion, UAE $<30 \mathrm{mg} / 24 \mathrm{~h}$ ) with creatinine-based estimated glomerular filtration rate $(e G F R) \geq 60 \mathrm{ml} / \mathrm{min} / 1.73 \mathrm{~m}^{2}$, without acute inflammatory disease, CVD, urinary infection, with no history or the presence of malignancy, hypo- and hyperthyroidism. For non-diabetic groups inclusion criterion was also women who were not taking any medicament therapy. Participants who had kidney dysfunction (eGFR $<60 \mathrm{ml} / \mathrm{min} / 1.73 \mathrm{~m}^{2}$ or UAE $\geq 30 \mathrm{mg} / 24 \mathrm{~h}$ ), Type 1 Diabetes Mellitus, morbid obesity (BMI) > $40 \mathrm{~kg} / \mathrm{m}^{2}$, hepatic dysfunction, pregnancy, alcohol abuse, were excluded from the study, as well as diabetic patients on insulin therapy and those on anti-inflammatory medications. For non-diabetic groups, exclusion criteria were also fasting glucose $\geq 6.1 \mathrm{mmol} / \mathrm{L}$, glycosylated hemoglobin (HbA1c) $>6 \%$ and any medication use.

Basic anthropometric measurements: body height $(\mathrm{cm})$, body weight $(\mathrm{kg})$ and waist circumference (WC) $(\mathrm{cm})$ were recorded. Weight was measured to the nearest $0.1 \mathrm{~kg}$ on a balance beam scale, with the subjects barefoot and with light clothing. Height was measured to the nearest $0.1 \mathrm{~cm}$ using a wall-mounted stadiometer, without shoes. Waist circumference was measured with the non-stretchable tape, over the unclothed abdomen at the midpoint between the lowest rib and the iliac crest. Measurements were made at the end of normal expiration. The tape was parallel to the floor and did not compress the skin. Body mass index was calculated as weight in kilograms divided by height in meters squared. Although our obese population consisted of slightly obese (overweight, $25 \leq \mathrm{BMI}<30 \mathrm{~kg} / \mathrm{m}^{2}$ ) and moderately obese $\left(30 \leq \mathrm{BMI}<40 \mathrm{~kg} / \mathrm{m}^{2}\right)$, for simplicity reasons, we referred to them as the obese participants. Blood pressure (BP) was measured with a sphygmomanometer after the subject had been seated for 15 minutes. Average of three measurements taken on the right arm was recorded. All measurements were taken by the same trained evaluator.

All the participants provided written informed consent. The study protocol was approved by the 
Ethical Committee of Primary Health Care Center in Podgorica and the research was carried out in compliance with the Declaration of Helsinki.

\section{Biochemical analyses}

Serum samples were divided into aliquots and stored at $-20^{\circ} \mathrm{C}$, without prior thawing and re-freezing before analyses, except for fasting glucose which was determined immediately after blood was drawn. Another aliquot was collecting as a whole blood in $\mathrm{K}_{2}$ EDTA for determination of glycosylated hemoglobin (HbA1c). Serum levels of glucose, total cholesterol, high density lipoprotein cholesterol (HDL-c), low density lipoprotein cholesterol (LDL-c) and triglycerides (TG) were measured spectrophotometrically using enzymatic procedures, while $\mathrm{HbA1c}$ and UAE were measured with immunoturbidimetric assay (Roche Cobas 400, Mannheim, Germany). RBP4 was determined using an immunonephelometric assay (Behring Nephelometer Analyzer, BN II, Marburg, Germany). Insulin was measured by chemiluminescent immunometric assay (AxSYM, Abbott, Abbott Park, Illinois, USA). Homeostasis model assessment of insulin resistance (HOMA-IR) was calculated: HOMA-IR=Fasting glucose $(\mathrm{mmol} / \mathrm{L}) \mathrm{x}$ fasting insulin $(\mu \mathrm{IU} / \mathrm{L}) / 22.5$. GFR was estimated using the using the Chronic Kidney Disease Epidemiology Collaboration Equation, CKD-EPI (14).

\section{Statistical analysis}

Statistical analyses were performed using SPSS statistical package (version 15.0 for Windows, SPSS, Chicago, IL, USA). Data are presented as mean \pm standard deviation, or median (interquartile range), or as counts and percentages. Differences between groups were evaluated with ANOVA (for normally distributed data) or Kruskall-Wallis test (for non-normally distributed data). A correlation analysis by Pearson's correlation coefficient was used to determine the relationship between RBP4 levels and other variables. Due to skewed distribution, log transformed insulin, HOMA-IR, HbA1c, triglycerides and UAE were used. Multiple regression analysis was performed to identify independent factors affecting RBP4 and to estimate the final predictors of its variability. A p value of $<0.05$ was considered as statistically significant.

\section{RESULTS}

Table 1 shows general clinical and biochemical characteristics of the study participants divided into three groups: normal weight, obese and obese diabetic postmenopausal women. There was significant increase in waist circumference, insulin resistance and triglycerides, as well as in blood pressure, but decrease in HDL-c across the study groups ( $\mathrm{p}<0.001)$. Moreover, serum RBP4 level was increased in obese groups as compared with the lean group ( $\mathrm{p}=0.033)$. However, there was no difference in serum RBP4 levels between obese non-diabetic and obese-diabetic women ( $\mathrm{p}=0.583)$.

The relationship between RBP4 and clinical and biochemical characteristics in obese non-diabetic and obese diabetic participants is presented in Table 2. Serum RBP4 did not correlate with anthropometric measurements or any indicator of glucose metabolism in diabetic group, whereas RBP4 correlated with creatinine $(\mathrm{r}=0.416, \mathrm{p}=0.003)$, eGFR $(\mathrm{r}=-0.304, \mathrm{p}=0.032)$ and triglycerides $(\mathrm{r}=0.484$, $\mathrm{p}<0.001)$. In obese non-diabetic group, correlations were observed with fasting glucose $(r=0.346$, $\mathrm{p}=0.014)$, insulin $(\mathrm{r}=0.292, \mathrm{p}=0.038)$, HOMA-IR $(\mathrm{r}=0.329 \mathrm{p}=0.020)$, HbA1c $(\mathrm{r}=0.326, \mathrm{p}=0.021)$, HDL-c $(\mathrm{r}=-0.316, \mathrm{p}=0.025)$, triglycerides $(\mathrm{r}=0.461$, $\mathrm{p}<0.001)$, systolic BP $(\mathrm{r}=0.286, \mathrm{p}=0.044)$, creatinine $(r=0.399, p=0.004)$, and eGFR $(r=-0.389$, $\mathrm{p}=0.005)$.

To determine which of the examined parameters were significantly associated with serum RBP4, we performed multiple linear regression analysis between RBP4 and all parameters in the whole group of obese participants. In multiple linear regression analysis only eGFR (Beta $=-0.188, \mathrm{p}=0.015)$ and triglycerides (Beta $=0.302, \mathrm{p}<0.001$ ) remained significant independent predictors of higher RBP4 levels (Table 3). These associations were independent of diabetes.

\section{DISCUSSION}

We reported higher levels of RBP4 in obese postmenopausal women, as compared with normal weight group. However, we did not find significant difference between obese non-diabetic and obese-diabetic women. Moreover, despite the observed correlation between RBP4 and glycemic control and IR 
TABLE 1. Demographic and general characteristics of studied women

\begin{tabular}{|c|c|c|c|c|}
\hline Variable & Normal weight $(n=50)$ & Obese $(n=50)$ & Obese diabetic $(n=50)$ & $\mathrm{p}$ \\
\hline Age (years) & $56.4 \pm 4.89$ & $57.7 \pm 6.34$ & $58.3 \pm 5.98$ & 0.240 \\
\hline $\mathrm{BMI}\left(\mathrm{kg} / \mathrm{m}^{2}\right)$ & $21.9 \pm 2.01$ & $30.1 \pm 3.35^{\text {аa }}$ & $29.9 \pm 2.75^{\text {аа }}$ & $<0.001$ \\
\hline WC $(\mathrm{cm})$ & $75.5 \pm 3.89$ & $99.5 \pm 7.80^{\mathrm{aa}}$ & $102.7 \pm 9.64^{\text {аa }}$ & $<0.001$ \\
\hline Fasting glucose (mmol/L) & $5.15 \pm 0.39$ & $5.45 \pm 0.41^{\text {aа }}$ & $8.05 \pm 2.44^{\text {aa,bb }}$ & $<0.001$ \\
\hline Fasting insulin $(\mu / \mathrm{U} / \mathrm{L})$ & $4.92(4.00-5.97)$ & $9.02(6.90-12.90)^{\text {aа }}$ & $10.70(6.30-18.20)^{\text {aа }}$ & $<0.001$ \\
\hline HOMA-IR & $1.09(0.98-1.34)$ & $2.20(1.66-3.09)^{\mathrm{aa}}$ & $3.33(2.23-6.87)^{\text {aa,bb }}$ & $<0.001$ \\
\hline $\mathrm{HbA} 1 \mathrm{c}(\%)$ & $4.95(4.80-5.10)$ & $5.50(5.30-5.60)$ & $6.70(6.30-7.30)^{a a, b b}$ & $<0.001$ \\
\hline $\mathrm{TC}(\mathrm{mmol} / \mathrm{L})$ & $6.39 \pm 0.98$ & $6.29 \pm 1.16$ & $6.13 \pm 1.07$ & 0.470 \\
\hline $\mathrm{HDL}-\mathrm{c}(\mathrm{mmol} / \mathrm{L})$ & $1.94 \pm 0.42$ & $1.47 \pm 0.365^{\text {aа }}$ & $1.31 \pm 0.37^{a a, b b}$ & $<0.001$ \\
\hline LDL-c (mmol/L) & $4.09 \pm 0.95$ & $4.15 \pm 1.24$ & $3.73 \pm 0.94$ & 0.098 \\
\hline TG (mmol/L) & $1.06(0.78-1.40)$ & $1.46(1.07-1.97)^{\text {aa }}$ & $1.81(1.42-2.49)^{a, b}$ & $<0.001$ \\
\hline $\mathrm{SBP}(\mathrm{mm} \mathrm{Hg})$ & $120 \pm 26.1$ & $145 \pm 15.0^{\text {aa }}$ & $145 \pm 15.9^{\text {aa }}$ & $<0.001$ \\
\hline $\mathrm{DBP}(\mathrm{mm} \mathrm{Hg})$ & $79.3 \pm 15.83$ & $91.6 \pm 9.81^{\text {aa }}$ & $89.6 \pm 13.62^{\text {aa }}$ & $<0.001$ \\
\hline Creatinine $(\mu \mathrm{mol} / \mathrm{L})$ & $52.8 \pm 6.06$ & $60.3 \pm 10.15^{\text {aa }}$ & $56.8 \pm 12.17^{\text {aa }}$ & 0.001 \\
\hline eGFR $\left(\mathrm{mL} / \mathrm{min} / 1.73 \mathrm{~m}^{2}\right)$ & $102(97-107)$ & $94(90-103)^{\text {aa }}$ & $99(95-104)^{\text {aa }}$ & $<0.001$ \\
\hline UAE (mg/24h) & $5.90(4.85-7.48)$ & $6.10(4.91-8.32)$ & $7.35(4.96-10.46)^{\mathrm{a}}$ & 0.055 \\
\hline RBP4 $(\mu \mathrm{g} / \mathrm{mL})$ & $38.60 \pm 9.91$ & $42.30 \pm 7.77^{\mathrm{a}}$ & $43.30 \pm 10.23^{\mathrm{a}}$ & 0.033 \\
\hline Antihypertensive drugs \% ( $\mathrm{n}$ ) & 0 & 0 & $86(43)$ & - \\
\hline Lipid lowering drugs (n) \% (n) & 0 & 0 & $72(36)$ & - \\
\hline Hypoglycemic drugs -metformin \% (n) & 0 & 0 & $100(50)$ & - \\
\hline Current smokers \% (n) & 0 & $10(5)$ & $14(7)$ & - \\
\hline Duration of diabetes (years) & - & - & $4.11 \pm 0.93$ & - \\
\hline
\end{tabular}

Data are presented as mean \pm standard deviation or median (interquartile range), or counts and percentages; ANOVA (for normally distributed data) or Kruskall-Wallis test (for non-normally distributed data) were used for testing the difference between groups; BMI-Body mass index; WC-Waist circumference; HOMA-IR-Homeostasis model of insulin resistance; HbA1c-glycosilated hemoglobin; TC-total cholesterol; HDL-c-High density lipoprotein cholesterol; LDL-c-Low density lipoprotein cholesterol; TG-Triglycerides, ${ }^{\text {aa }} p<0.001$ compared with normal weight group, ${ }^{a} p<0.05$ compared with normal weight group, ${ }^{b b} p<0.001$ compared with obese non-diabetic group, ${ }^{b} p<0.05$ compared with obese non-diabetic group

in obese non-diabetic participants, triglycerides and eGFR were found to be the best predictors of RBP4 levels.

Namely, the mechanism of the effect of diabetes on the RBP4 concentration remains unclear since discrepant results were obtained from many studies. Results in the present study are in concordance with results by An et al. (15) who did not find the difference in serum RBP4 concentration between postmenopausal women with T2DM and healthy postmenopausal control, after adjustment for age and BMI. They also demonstrated that serum RBP4 levels even had no correlation with the prevalence of T2DM in postmenopausal women like some previous studies, which have failed to report the involvement of RBP4 in the development of T2DM in humans $(16,17)$.
Comucci et al. (18) also did not find the difference between obese and obese-diabetic participants, but unexpectedly, they reported lower RBP4 levels in obese and obese diabetic subjects compared to control, lean group. On the contrary, higher levels of RBP4 in obese diabetic subjects as compared with obese non-diabetic ones were reported by some other colleagues (19), showing that serum RBP4 levels were highly associated with IR (20) and were increased in diabetic patients $(21,22)$.

Lack of significant difference in serum RBP4 between obese non-diabetic and obese-diabetic women found in our present study may partially be explained by the fact that diabetic participants were not able to exclude metformin, which may underestimate RBP4 levels. Moreover, antihypertensive medications were not excluded in diabetic 
TABLE 2. Pearson's correlation coefficients ( $r$ ) of RBP4 and studied parameters among obese non-diabetic and obese diabetic postmenopausal women

\begin{tabular}{|c|c|c|c|c|}
\hline \multirow[t]{2}{*}{ Variable } & \multicolumn{2}{|c|}{$\begin{array}{l}\text { Obese } \\
(n=50)\end{array}$} & \multicolumn{2}{|c|}{$\begin{array}{l}\text { Obese diabetic } \\
\quad(n=50)\end{array}$} \\
\hline & $r$ & $p$ & $r$ & $p$ \\
\hline Age (years) & 0.180 & 0.212 & -0.022 & 0.879 \\
\hline BMI (kg/m²) & -0.055 & 0.706 & 0.070 & 0.630 \\
\hline WC $(\mathrm{cm})$ & 0.056 & 0.699 & -0.137 & 0.343 \\
\hline Fasting glucose (mmol/L) & 0.346 & 0.014 & 0.092 & 0.525 \\
\hline Log insulin $(\mu / \mathrm{U} / \mathrm{L})$ & 0.294 & 0.038 & 0.016 & 0.910 \\
\hline Log HOMA-IR & 0.329 & 0.020 & 0.083 & 0.568 \\
\hline Log HbA1c (\%) & 0.326 & 0.021 & -0.114 & 0.430 \\
\hline $\mathrm{TC}(\mathrm{mmol} / \mathrm{L})$ & 0.232 & 0.104 & 0.179 & 0.215 \\
\hline HDL-c (mmol/L) & -0.316 & 0.025 & -0.107 & 0.459 \\
\hline LDL-c (mmol/L) & 0.191 & 0.183 & 0.218 & 0.127 \\
\hline Log TG (mmol/L) & 0.461 & $<0.001$ & 0.484 & $<0.001$ \\
\hline $\mathrm{SBP}(\mathrm{mm} \mathrm{Hg})$ & 0.286 & 0.044 & 0.180 & 0.211 \\
\hline $\mathrm{DBP}(\mathrm{mm} \mathrm{Hg})$ & 0.188 & 0.191 & 0.117 & 0.416 \\
\hline Creatinine $(\mu \mathrm{mol} / \mathrm{L})$ & 0.399 & 0.004 & 0.416 & 0.003 \\
\hline eGFR $\left(\mathrm{mL} / \mathrm{min} / 1.73 \mathrm{~m}^{2}\right)$ & -0.389 & 0.005 & -0.304 & 0.032 \\
\hline Log UAE (mg/24 h) & 0.134 & 0.352 & 0.049 & 0.735 \\
\hline
\end{tabular}

BMI-Body mass index; WC-Waist circumference; log HOMA-IR-Logarithmically transformed Homeostasis model assessment of insulin resistance; log $\mathrm{HbA} 1 \mathrm{c}$-Logarithmically transformed glycosylated hemoglobin; TC-Total cholesterol; HDL-C-High density lipoprotein cholesterol; LDL-C-Low density lipoprotein cholesterol; log TG-Logarithmically transformed triglycerides; SBP-Systolic blood pressure; DBP-Diastolic blood pressure; eGFR-Estimated glomerular filtration rate; log UAE- Logarithmically transformed urinary albumin excretion

TABLE 3. Multiple regression analysis with RBP4 as dependent variable in all obese women

\begin{tabular}{lccc}
\hline Independent variable & $\mathrm{B}$ & Std Beta & $\mathrm{p}$ \\
\hline logHOMA-IR & 0.952 & 0.111 & 0.166 \\
$\log T \mathrm{G}$ & 13.637 & 0.302 & $<0.001$ \\
eGFR & -0.225 & -0.188 & 0.015 \\
SBP & 0.058 & 0.150 & 0.089 \\
\hline
\end{tabular}

RBP4-retinol-binding protein 4; LogHOMA-IR-Logarithmically transformed homeostasis model assessment of insulin resistance; LogTG-Logarithmically transformed triglycerides; eGFR-Estimated glomerular filtration rate; SBP-Systolic blood pressure

individuals, which can also influence serum RBP4 levels $(23,24)$ and IR (25-27). Nevertheless, An et al. (15) also found insignificant difference in serum RBP4 between newly diagnosed T2DM postmenopausal women who were not under any medicament therapy and healthy postmenopausal control. On the other hand, our results are discrepant with Shaker and colleagues (28), who reported higher plasma RBP4 levels in obese T2DM even with the treatment with oral hypoglycemic agents. However, this elevation may partially be due to longer duration of diabetes and potential renal impairment in diabetic individuals, since they did not take into account renal function in their study. Higher RBP4 levels in T2DM were also reported by Takebayashi et al. (21), but these patients had higher BMI as compared to the non-diabetic group, which may contribute the higher RBP4 levels in diabetic individuals, too. Their participants also had longer duration of diabetes than our study participants. As far as the current study is concerned, we included in our study only patients with eGFR $\geq 60 \mathrm{~mL} / \mathrm{min} / 1.73 \mathrm{~m} 2$, and did not record significant difference in BMI and eGFR between obese diabetic and obese non-diabetic group.

Furthermore, in the current study we did not record significant correlation between RBP4 and anthropometric parameters in obese individuals. This may be explained by the fact that we did not use the precise imaging techniques to measure adipose tissue depots, but we took simple anthropometric measurements, like the majority of the previous studies. Indeed, Lee et al. (29) showed that obese subjects without visceral adiposity had lower serum RBP4 levels than lean subjects with visceral adiposity. As our study groups were consisted of only postmenopausal women, and the postmenopausal status is characterized with adipose tissue distribution towards visceral one (2), central obesity as measured by WC seemed to be better indicator of obesity, rather than the overall one, as measured by BMI. Namely, visceral adipose tissue is a source of variety adipocitokines which reach the liver in high concentrations via the portal vein and directly impacts on hepatic insulin sensitivity which progressively increases hepatic and adipose-tissue insulin resistance (7).

However, the association of RBP4 with HOMA-IR and glycemic control disappeared after multiple regression analysis, whereas only eGFR and triglycerides remained independent predictors of RBP4. It is in accordance with some other studies (30), thus suggesting that previously reported associations between RBP4 and insulin resistance 
may be influenced by triglycerides and free fatty acid serum concentrations.

RBP4 independently correlated with triglycerides even in lean and healthy adults, as shown by Ebert et al. (31).

Sun et al. (32) found a significant positive association between plasma RBP4 concentrations and risk of developing T2DM after 6-y follow-up. They also observed that incidence of type 2 diabetes was elevated in the top category of RBP4 regardless of the amounts of HOMA-IR, suggesting that RBP4 may increase the risk of T2DM through pathway(s) not largely overlapping with insulin resistance.

The results on the associations of RBP4 with markers of kidney function were also observed in some previous studies (9), indicating that kidney dysfunction might be determinant of higher RBP4 levels. This suggests the necessity of taking into account renal function when examining RBP4 in obesity and diabetes, knowing that kidneys play an important role in retinol homeostasis, which is regulated by glomerular filtration and subsequent reabsorption of RBP4 into the proximal tubular cells (33).

Our study has some limitations. Due to its cross-sectional design, the causal relationship between serum RBP4 and examined parameters in postmenopausal women could not be established. Furthermore, as our study was based on small sample size, selection bias might have affected the outcome of the study. Thus, larger sample size in general population may be required to confirm our results. Also, diabetic postmenopausal women were not asked to stop taking their medications, such as antihypertensive, lipid-lowering drugs and metformin which might affect the outcome of our study.

\section{CONCLUSION}

We reported higher levels of RBP4 in obese postmenopausal women, as compared with normal weight group. However, serum RBP4 was not increased in obese type 2 diabetic postmenopausal women as compared with obese non-diabetic women, but is associated with eGFR and triglycerides independently of diabetes. Prospective studies and further analyses are needed to clarify the underlying mechanism of the association between RBP4, obesity and T2DM.

\section{CONFLICT OF INTEREST}

The authors declare no conflicts of interest.

\section{REFERENCES}

1. Lovejoy JC, Champagne CM, de Jonge L, Xie H, Smith SR. Increased visceral fat and decreased energy expenditure during the menopausal transition. Int J Obes (Lond) 2008; 32: 949-958. http://dx.doi.org/10.1038/ ijo.2008.25

2. Toth MJ, Tchernof A, Sites CK, Poehlman ET. Effect of menopausal status on body composition and fat distribution. Int J Obes Relat Metab Disord 2000; 24: 226-231. http://dx.doi.org/10.1038/sj.ijo.0801118.

3. Barnes AS. The Epidemic of Obesity and Diabetes-Trends and Treatments. Tex Heart Inst J 2011; 38 (2): 142-144.

4. Ministarstvo zdravlja Crne Gore, Akcioni plan za ishranu i bezbjednost hrane Crne Gore, 2010-2014, Podgorica 2010 (Ministry of Health of Montenegro, Action plan for nutrition and food safety of Montenegro, 20102014, Podgorica 2010).

5. International Diabetes Federation: IDF Diabetes Atlas. $6^{\text {th }}$ edition. Brussels, Belgium: International Diabetes Federation; 2013:30 (http://www.idf.org/diabetesatlas).

6. The Performance of Public Health-care Systems in South-East Europe -A comparative qualitative study. Friedrich-Ebert-Stiftung Regional Project for Labour Relations and Social Dialogue in South East Europe. Belgrade, Serbia 2014.

7. Cao H. Adipocytokines in obesity and metabolic disease. J Endocrinol. 2014; 220: T47-T59. http://dx.doi.org/10.1530/JOE-13-0339.

8. Papaetis GS, Papakyriakou P, Panagiotou TN. Central obesity, type 2 diabetes and insulin: exploring a pathway full of thorns. Arch Med Sci 2015; 11, 3: 463-482. http://dx.doi.org/10.5114/aoms.2015.52350

9. Junjun W, Jia W, Jiaxi S, Dongmei N, Yonghui S, Fang Z, et al.. Associations of RBP4 with lipid metabolism and renal function in diabetes mellitus. Eur J Lipid Sci Technol 2013; 115: 831-837. http://dx.doi.org/10.1002/ ejlt.201200393.

10. Ribel-Madsen R, Friedrichsen M, Vaag A, Poulsen P. Retinol-binding protein 4 in twins: regulatory mechanisms and impact of circulating and tissue expression levels on insulin secretion and action. Diabetes 2009; 58: 54-60. http://dx.doi.org/10.2337/db08-1019.

11. Broch M, Vendrell J, Ricart W, Richart C, Fernández-Real JM. Circulating retinol-binding protein-4, insulin sensitivity, insulin secretion, and insulin disposition index in obese and nonobese subjects. Diabetes Care 2007; 30: 1802-1806. http://dx.doi.org/10.2337/dc06-2034.

12. von Eynatten M, Lepper PM, Liu D, et al. Retinol-binding protein 4 is associated with components of the metabolic syndrome, but not with insulin resistance, in men with type 2 diabetes or coronary artery disease. Diabetologia 2007; 50: 1930-1937. http://dx.doi.org/10.1007/s00125-007-0743-8.

13. Yao-Borengasser A, Varma V, Bodles AM, et al. Retinol binding protein 4 expression in humans: relationship to insulin resistance, inflammation, and response to pioglitazone. J Clin Endocrinol Metab 2007; 92: 2590-2597. http://dx.doi.org/10.1210/jc.2006-0816.

14. Levey AS, Stevens LA, Schmid CH, Zhang YL, Castro AF $3^{\text {rd }}$, Feldman HI, et al. CKD-EPI (Chronic Kidney Disease Epidemiology Collaboration). Anew equation to estimate glomerular filtration rate. Ann Intern Med 2009; 150 (9): 604 - 612. http://dx.doi.org/10.7326/0003-4819-150-9-200905050-00006.

15. An C, Wang H, Liu X, Li Y, Su Y, Gao X, Jiang W. Serum retinol-binding protein 4 is elevated and positively associated with insulin resistance in postmenopausal women. Endocr J 2009; 56(8): 987-996. http://dx.doi. org/10.1507/endocrj.K09E-096.

16. Janke J, Engeli S, Boschmann M, Adams F, Böhnke J, Luft FC, et al. Retinol-binding protein 4 in human obesity. Diabetes 2006; 55: 2805-2810. http://dx.doi.org/10.2337/db06-0616.

17. Kim HM, Park J, Ryu SY, Kim J. The effect of menopause on the metabolic 
syndrome among Korean women: the Korean National Health and Nutrition Examination Survey, 2001. Diabetes Care 2007; 30:701-706. http://dx.doi. org/10.2337/dc06-1400.

18. Comucci EB, Vasques ACJ, Geloneze B, Calixto AR, Pareja JC, Tambascia MA. Serum levels of retinol binding protein 4 in women with different levels of adiposity and glucose tolerance. Arq Bras Endocrinol Metab 2014; 58(7): 709-714. http://dx.doi.org/10.1590/0004-2730000002431.

19. Budhitresna AAG, Suastika K, Budhiarta AAG, Santoso A. High Plasma Retinol-Binding Protein 4 Levels as Risk Factor of Type 2 Diabetes Mellitus in Abdominal Obesity. J Asian Fed End Soc 2013; 28(2): 129-133.

20. Gavi S, Stuart LM, Kelly P, Melendez MM, Mynarcik DC, Gelato MC, et al. Retinol-binding protein 4 is associated with insulin resistance and body fat distribution in non-obese subjects without type 2 diabetes. J Clin Endocrinol Metab 2007; 92:1886-1890. http://dx.doi.org/10.1210/jc.2006-1815.

21. Takebayashi K, Suetsugu M, Wakabayashi S, Aso Y, Inukai T. Retinol Binding Protein-4 Levels and Clinical Features of Type 2 Diabetes Patients. J Clin Endocrinol Metab 2007; 92: 2712-2719. http://dx.doi.org/10.1210/ jc.2006-1249.

22. Cho YM, Youn BS, Lee H, Lee N, Min SS, Kwak SH, et al. Plasma retinol-binding protein-4 concentrations are elevated in human subjects with impaired glucose tolerance and type 2 diabetes. Diabetes Care 2006; 29: 2457-2461. http://dx.doi.org/10.2337/dc06-0360.

23. Derosa G, Maffioli P, Salvadeo SA, Ferrari I, Gravina A, Mereu R, et al. Differential effects of candesartan and olmesartan on adipose tissue activity biomarkers in type II diabetic hypertensive patients. Hypertens Res 2010; 33: 790-795. http://dx.doi.org/10.1038/hr.2010.85.

24. Derosa G, Maffioli P, Ferrari I, Palumbo I, Randazzo S, Fogari E, et al. Different actions of losartan and ramipril on adipose tissue activity and vascular remodeling biomarkers in hypertensive patients. Hypertens Res 2011; 34: 145-151. http://dx.doi.org/10.1038/hr.2010.205.

25. Schmieder RE. Mechanisms for the clinical benefits of angiotensin II receptor blockers. Am J Hypertens 2005; 18: 720-730. http://dx.doi. org/10.1016/j.amjhyper.2004.11.032.

26. Chu KY, Lau T, Carlsson PO, Leung PS. Angiotensin II type 1 receptor blockade improves beta-cell function and glucose tolerance in a mouse model of type 2 diabetes. Diabetes 2006; 55: 367-374. http://dx.doi. org/10.2337/diabetes.55.02.06.db05-1022.

27. Koyama Y, Kodama K, Suzuki M, Harano Y. Improvement of insulin sensitivity by a long-acting nifedipine preparation (nifedipine-CR) in patients with essential hypertension. Am J Hypertens 2002; 15: 927-931. http://dx.doi. org/10.1016/S0895-7061(02)03019-4.

28. Shaker O, El-Shehaby A, Zakaria A, Mostafa N, Talaat S, Katsiki N, et al. Pasma visfatin and retinol binding protein-4 in patients with type 2 diabetes mellitus and their relationship to adiposity and fatty liver. Clin Biochem 2011; 44: 1457-1463. http://dx.doi.org/10.1016/j.clinbiochem.2011.08.1148

29. Lee JW, Im JA, Lee HR, Shim JY, Youn BS, Lee DC. Visceral Adiposity Is Associated with Serum Retinol Binding Protein-4 Levels in Healthy Women. Obesity 2007; 15: 2225-2232. http://dx.doi.org/10.1038/oby.2007.264.

30. Flehmig G, Scholz M, Klöting N, Fasshauer M, Tönjes A, Stumvoll M, et al. Identification of Adipokine Clusters Related to Parameters of Fat Mass, Insulin Sensitivity and Inflammation. PLoS ONE 2014; 9(6): e99785. http:// dx.doi.org/10.1371/journal.pone.0099785.

31. Ebert T, Roth I, Richter J, Tönjes A, Kralisch S, Lossner U, et al. Different associations of adipokines in lean and healthy adults. Horm Metab Res 2014; 46(1): 41-47.

32. Sun L, Qi Q, Zong G, Ye X, Li H, Liu X, et al. Elevated plasma retinol-binding protein 4 is associated with increased risk of type 2 diabetes in middle-aged and elderly Chinese adults. J Nutr 2014; 144(5): 722-728. http:// dx.doi.org/10.3945/jn.113.189860

33. Murata M, Saito T, Otani T, Sasaki M, Ikoma A, Toyoshima H, et al. An increase in serum retinol-binding protein 4 in the type 2 diabetic subjects with nephropathy. Endocr J 2009; 56(2): 287-294. http://dx.doi. org/10.1507/endocrj.K08E-242. 